\title{
Video-intuboscopic monitoring of tracheal intubation in pediatric patients
}

\author{
Markus Weiss MD, \\ Uwe Schwarz MD, \\ Claudia M. Dillier MD, \\ Andreas Ch. Gerber MD
}

Purpose: To evaluate the efficacy of video-intuboscopic monitoring during orotracheal intubation in a pediatric anesthesia teaching unit.

Methods: In 100 pediatric patients direct laryngoscopy performed by residents or nurse anesthetists was monitored on a video display using a flexible, ultralight video-endoscopic system (O.D. $2.8 \mathrm{~mm} /$ length $1.8 \mathrm{~m}$ ) within the endotracheal tube (ETT). Best direct laryngoscopic view was assessed by the intubator. The instructor observed the intubation procedure on the video display and noted number of intubation attempts, best laryngoscopic monitor view, tube passage through the larynx and final tube position. If required he gave instructions or corrections. After removal of the laryngoscope, tracheal tube position was adjusted using the monitor view. Difficulties attributed to the fibreoptic endoscope during intubation and removal from the ETT were recorded.

Results: The trachea was successfully intubated at the first attempt in all patients. The supervisor detected one esophageal and 12 endobronchial intubations that were immediately corrected before starting ventilation. Final visualized endotracheal tube adjustment above the carina was possible in all patients except in one with copious tracheal secretions. Compared with direct laryngoscopy the video display provided an improved view of the vocal cords during intubation. In six patients direct laryngoscopy was difficult but the tracheas were intubated using the monitor view. No difficulties with the equipment were encountered except that the black coated endoscope compromised recognition of the black ETT depth-markings in small tubes.

Conclusions: Video-intuboscopic monitoring is a useful monitor of tracheal intubation. "The improved view of the cords may provide assistance during difficult laryngoscopy.

Objectif : Évaluer l'efficacité d'un monitorage vidéoscopique de l'intubation orotrachéale réalisée à l'unité d'enseignement d'anesthésie pédiatrique.

Méthode : Une laryngoscopie directe a été réalisée chez 100 patients pédiatriques par des résidents ou des infirmières anesthésistes et a été contrôlée sur écran vidéo en utilisant un système vidéo-endoscopique flexible et ultraléger (diamètre extérieur de 2,8 mm / longueur de I,8 m) à l'intérieur du tube endotrachéal (TET). La meilleure vision de laryngoscopie directe a été évaluée par l'étudiant. L'instructeur a observé l'intubation sur l'écran vidéo et a noté le nombre d'essais, la meilleure vue laryngoscopique sur écran, le passage du tube au travers du larynx et la position finale du tube. II a donné des instructions ou fait des corrections au besoin. Après le retrait du laryngoscope, la position du TET a été ajustée selon la vision sur écran. On a enregistré les difficultés attribuées au fibroscope pendant l'intubation et le retrait du TET.

Résultats : L'intubation a été réussie au premier essai. Le superviseur a détecté une intubation œsophagienne et 12 endobronchiques qui ont été immédiatement corrigées avant de commencer la ventilation. Un ajustement final du TET visualisable au-dessus de la carène a été possible chez tous les patients, sauf dans un cas d'abondantes sécrétions trachéales. Comparé à la laryngoscopie directe, l'affichage vidéo a fourni une meilleure vue des cordes vocales pendant l'intubation. Chez six patients, la laryngoscopie directe a été difficile, mais réussie grâce à l'image projetée sur écran. L'équipement n'a pas présenté de difficulté, si ce n'est l'enduit noir de l'endoscope qui a compromis la reconnaissance des marques noires de graduation sur le TET de petit calibre.

Conclusion : Le monitorage vidéoscopique est utile pour l'intubation endotrachéale. La vision supérieure des cordes vocales peut faciliter une laryngoscopie difficile.

From the Department of Anaesthesia, University Children's Hospital, Steinwiesstrasse 75, 8032 Zurich, Switzerland. Address correspondence to: Dr. Markus Weiss. Phone: +41-1-266-77-53; Fax: +41-1-266-71-68; E-mail: markus.weiss@kispi.unizh.ch Accepted for publication August 31, 2000. 


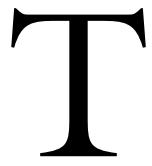

EACHING and supervising tracheal intubation in pediatric anesthesia is limited by narrow airway spaces so that the instructor cannot see what the laryngoscopist visualizes. Because of low pulmonary reserves and high oxygen consumption, the time for a single intubation attempt is limited and accidental esophageal or bronchial intubation may result in profound hypoxemia, until the problem is recognized and corrected.

Video-intuboscopy is a recently presented endoscopic technique to monitor or to guide the endotracheal tube (ETT) during conventional laryngoscopy. ${ }^{1}$ This can be performed using a flexible video-optical intubation stylet or a visualized endotracheal tube (VETT). ${ }^{1-4}$ Both devices have integrated optical and illumination fibres leading from their tip directly to a video monitor system. They can be used during conventional laryngoscopy to give a display from the intubation procedure without jeopardizing the laryngoscopist. During teaching, on-line transmission of the view from the ETT tip to a video display enables the supervisor to follow, teach and correct the intubation procedure and to immediately confirm correct tracheal tube position. ${ }^{1,5}$

The aim of the study was to evaluate the benefit of video-intuboscopic monitoring during tracheal intubation in a pediatric anesthesia teaching unit.

Methods

With hospital ethics committee approval, 100 children, ASA 1 or 2, aged between one month and $16 \mathrm{yr}$, scheduled for elective surgery requiring tracheal intubation were enrolled into the study.

Before starting anesthesia, a flexible, lightweight $1.8 \mathrm{~m}$ long fibreoptic endoscope (O.D. $2.8 \mathrm{~mm}$; manufacturer: VOLPI AG, Schlieren, Switzerland) was inserted into the endotracheal tube, but not protruding from its tip, and locked at the ETT connector using a sliding adapter (Figure 1). The fibreoptic endoscope, carrying optic and light transmitting fibres, was connected to a compact video-endoscopy monitor system (Acutronic Medical Systems AG, Hirzel, Switzerland)

Premedication, induction of anesthesia (inhalational or intravenous) depended upon the requirements and preference of the child. Conventional intubation was performed under deep inhalational anesthesia with or without muscle paralysis. Tracheal intubations were performed by residents or nurse anesthetists with varied experience in tracheal intubation.

Best direct laryngoscopic view using a straight laryngoscope blade was assessed by the laryngoscopist according to the classification of Cormack and

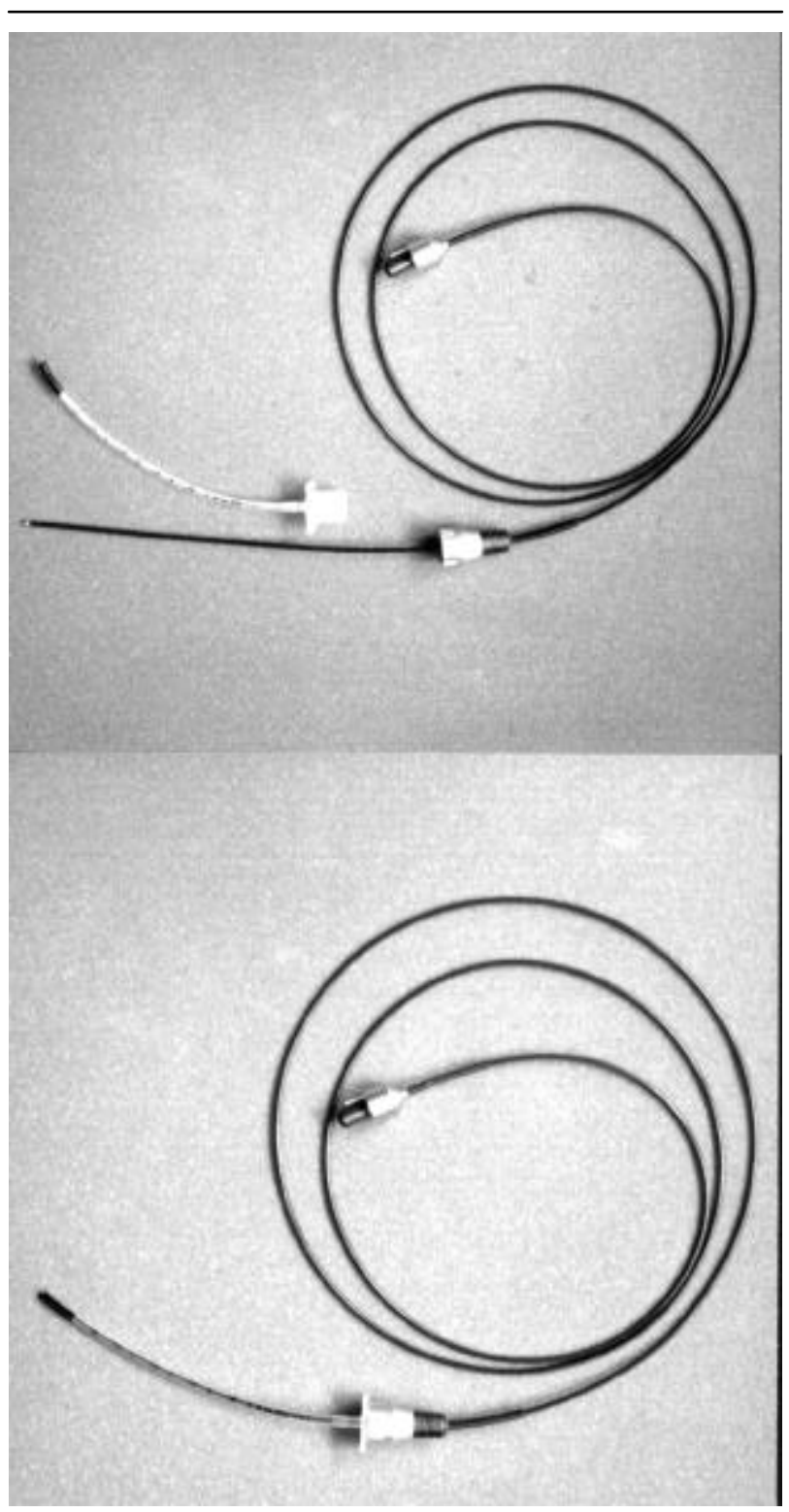

FIGURE 1 Endotracheal tube (ID $3 \mathrm{~mm}$ ) and ultrathin fibreoptic endoscope (OD: $2.8 \mathrm{~mm}$ ) with sliding adapter (top). The endoscope is inserted into the tracheal tube not protruding its tip and locked with the sliding adapter at the ETT connector (bottom).

Lehane. ${ }^{6}$ The trachea was intubated under direct vision and the tracheal tube was subsequently positioned according to the black ETT depth-marking (proximal end just visible above the vocal cords), the ETT cuff or the estimated required depth.

If direct laryngoscopic view of the vocal cords was obstructed by the epiglottis, the laryngoscopist was allowed to place the ETT tip below the epiglottis and 
subsequently to guide the endotracheal tube through the glottic opening using the video view from the ETT tip.

The consultant anesthesiologist provided normal assistance and observed the intubation procedure on the video display (Figure 2). In particular, the instructor noted number of intubation attempts, best laryngoscopic monitor view, tube passage through the larynx and final tube position. If required, he gave instructions or made corrections. Tracheal intubation was interrupted by mask ventilation, if pulse oxymetric measured arterial saturation decreased below $92 \%$.

In a second step, after removal of the laryngoscope the ETT tip was re-adjusted $2 \mathrm{~cm}$ above the tracheal carina, by drawing back the ETT together with the fibreoptic endoscope (Figure 2). Subsequently, the fibreoptic endoscope was removed from the ETT and the patient was connected to the ventilator.

Difficulties attributed to the fibreoptic endoscope during intubation and removal from the ETT were recorded. In addition, problems related to tracheal tube position during the further course of anesthesia were noted.

\section{Results}

In one hundred children aged from $0.3-14.3 \mathrm{yr}(4.9$ \pm 2.4 ) the tracheas were successfully intubated at the first attempt without arterial oxygen desaturation. Most underwent otorhinolaryngologic surgery requiring a preformed RAE tube.

Video-intuboscopic monitoring revealed endobronchial tube position in 12 patients during intubation. These were recognized by the supervisor and immediately corrected before starting ventilation. Endobronchial displacement of initially correctly placed ETTs were recognized in 11 children during removal of the laryngoscope and positioning the head in a neutral position. They were withdrawn under visual control and taped in the correct position.

Esophageal intubation was detected by the instructor in a five year old girl during the intubation procedure. The tube was immediately drawn back and the trachea was intubated in the same intubation attempt without arterial oxygen desaturation.

Direct laryngoscopic view was classified as grade I in 66, grade II in 28 and Grade III in 6 patients, while the video-display provided full view of the vocal cords (grade I) during intubation in all patients (Figure 2). In four patients in whom a floppy epiglottis obstructed direct laryngoscopic view to the cords (grade III), the tracheas were successfully intubated using the view from the ETT tip to guide the endotracheal tube beyond the epiglottis into the trachea. In two children

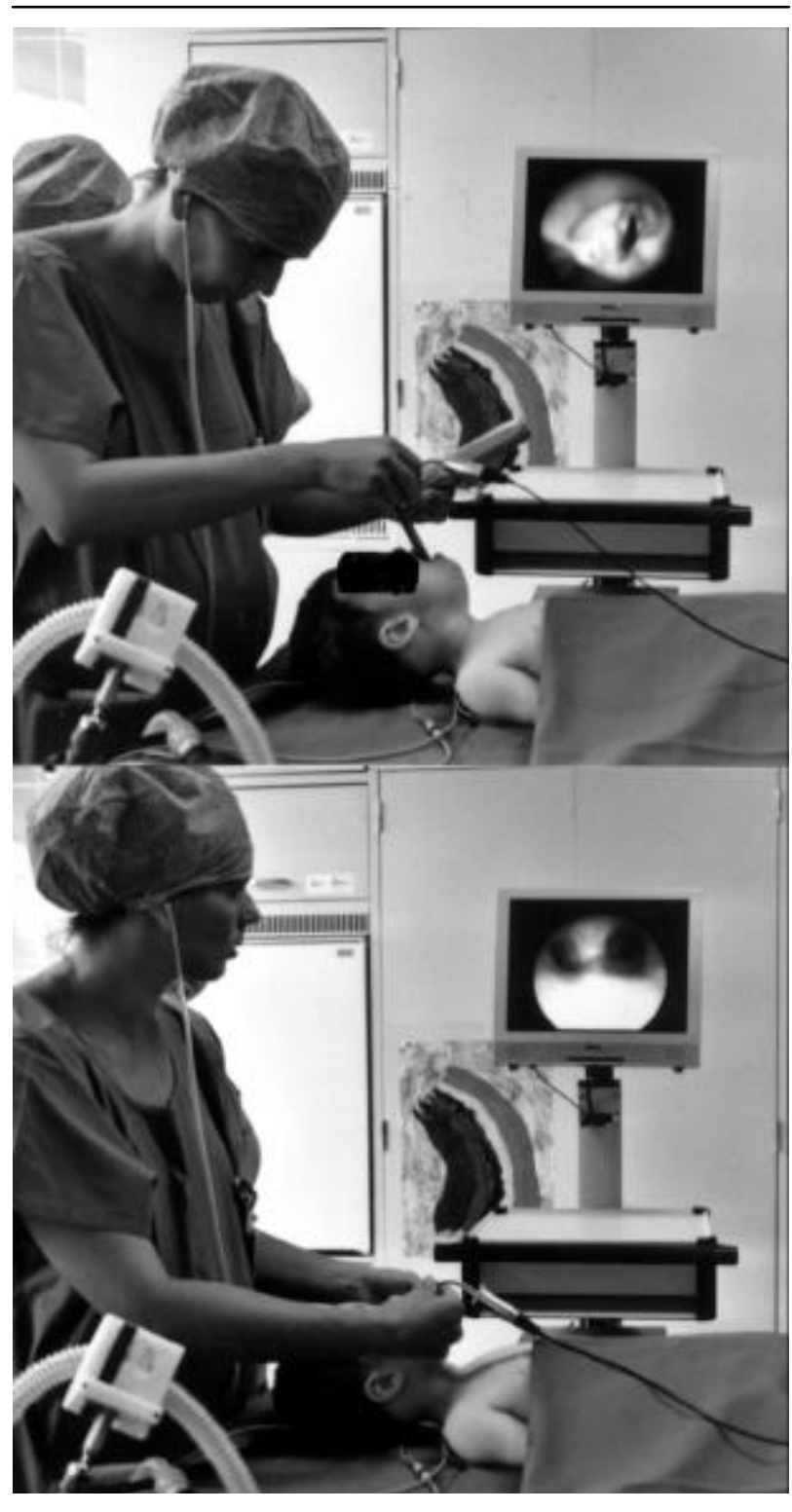

FIGURE 2 During conventional laryngoscopy the monitor view allows the supervisor to follow the endotracheal tube tip (top). Final endotracheal tube position is verified and adjusted $2 \mathrm{~cm}$ above the tracheal carina using the endoscopic monitor view (bottom).

with loose upper teeth, only a grade III view was obtained with direct laryngoscopy to avoid further dental damage. Intubation was successful using the video-assisted intubation technique.

Final adjustment of the endotracheal tube $2 \mathrm{~cm}$ above the tracheal carina under visual control was possible in all patients except in one child with copious tracheal secretions. No further problems with ETT position were recorded during the intraoperative 
course. No difficulties with the endoscopic equipment during intubation or removal from the ETT were stated, except that the black coated endoscope within the ETT compromised the recognition of the black ETT depth-markings on small tubes.

\section{Discussion}

We have evaluated efficacy of monitoring the ETT tip during endotracheal intubation in children using an ultrathin video-fibreendoscopic system within the tracheal tube. The main finding was, that video-intuboscopic monitoring in a teaching situation enabled the supervisor to recognize and correct malpositioned endotracheal tubes instantly.

Monitoring the tip of an endotracheal tube was first published by Murphy 1967. ${ }^{7}$ He used the view from the ETT tip achieved by a flexible, non-stearable choledochoscope within the tube for nasal intubation. Video-monitoring of the ETT tip was first reported by Vacanti and Roberts in 1992. ${ }^{8}$ They placed a fibreoptic endoscope adjacent to a malleable stylet in an oral endotracheal tube and connected the endoscope to a video-monitor system. The video view from the tube tip was used to assess the effect of various manipulations on access to the trachea during blind oral intubation.

The present intubation technique using an ultrathin, lightweight fibreoptic endoscope to monitor the ETT tip, provides a video-display from the intubation procedure during conventional intubation without jeopardizing the operator or the intubation process. The main advantage of video-intuboscopic intubation monitoring in our study was rapid and reliable recognition and instantly correction of accidentially malplaced endotracheal tubes by the supervisor. Immediate recognition and correction of an esophageal or bronchial inserted tracheal tube is important to avoid potentially serious complications. Thus, in addition to pulse oximetry and capnography, the video-intuboscopic technique may become a valuable aid for rapid tracheal tube position confirmation in anesthesia teaching units or in high risk patients requiring tracheal intubation. ${ }^{9}, 10$

A further advantage of video-intuboscopic monitoring was endoscopic adjustment of the tracheal tube tip within the trachea. Alteration of the head position during the operative course or placement of a tongue depressor can result in considerable movement of the ETT within the trachea of pediatric patients. ${ }^{11}$ Thus, an initially well working tracheal tube in the lower or upper trachea is at risk for endobronchial intubation or accidental extubation with possible dislocation of the ETT into the upper esophagus. In addition, an initially correctly placed endotracheal tube can become displaced during removal of the laryngoscope blade and release of retroflexion of the neck after direct laryngoscopy. Thus, accurate final placement of the ETT at a safe distance from the tracheal carina is essential, especially in neonates and small children. However, clinical studies in larger populations are needed to evaluate the benefit of visualized ETT placement compared with conventional methods in pediatric anesthesia or pediatric intensive care.

An important benefit of the technique was that, in six patients, the monitor view from the ETT tip helped to guide the tube into the trachea. Although the tip of the fibreoptic endoscope was not malleable or steerable, the preformed, curved RAE tube, used in these patients allowed to direct the ETT around the floppy, large epiglottis, obstructing the view to the cords. Although the operators were experienced with video-optical intubation stylets from earlier intubation mannequin studies, the familiar nature of the videoassisted intubation technique was reflected by the high success rate in all six patients. ${ }^{12}$ Because the fibreoptic endoscope does not interfere with conventional intubation, such an "optic cable" can be inserted prophylactically within the ETT in high risk patients before starting anesthesia. If unexpected difficulties with laryngoscopy arise, it provides rapid endoscopic intubation assistance, otherwise, it is used for immediate confirmation of tracheal tube position.

The present technique allows monitoring of the passage of the ETT through the larynx to the carina. No information about performance of direct laryngoscopy are provided on the video display. In contrast, video-transmission of the view from the distal laryngoscope blade as described by Roberts gives in additional display of all the anatomical structures during direct laryngoscopy. ${ }^{13}$

A further limitation of the technique is the high cost of the optical equipment. Fibreoptic endoscopy for airway management is expensive and the equipment requires much time for cleaning, sterilisation and preparation. The presented ultrathin fibrescope is a low-cost endoscope (1500 Can \$) without the facility either to manipulate the tip or to perform suction. Equipped with a proximal viewfinder or and light connector, it can be used with existing video-endoscopy monitoring systems in the OR or ICU.

In conclusion, video-intuboscopic monitoring of tracheal intubation can facilitate supervision of intubation in pediatric patients and is useful for early recognition and correction of malpositioned endotracheal tubes. The better view of the cords obtained by the video-endoscopic system during intubation provides a valuable assist during difficult laryngoscopy. 


\section{References}

1 Weiss $M$. Video-Intuboscopy: a new aid to routine and difficult tracheal intubation. Br J Anaesth 1998; 80: 525-7.

2 Gutstein $H B$. Use of the Bullard laryngsocope and lightwand in pediatric patients. Anesth Clin North Am 1998; 16: 795-812.

3 Gravenstein D, Melker RJ, Lampotang S. Clinical assessment of a plastic optical fiber stylet for human tracheal intubation. Anesthesiology 1999; 91: 648-53.

4 Frass M, Kofler J, Thalhammer F, et al. Clinical evaluation of a new visualized endotracheal tube (VETT). Anesthesiology 1997; 87: 1262-3.

5 Pollack CV Jr, Bailey BB, Jorden RC, Mackin RA ED clinical trial of a fiberoptic-enhanced endotracheal tube for intubation monitoring, tube placement confirmation, and difficult airway management. Annual Meeting of the Society for Academic Emergency Medicine, Washington D.C., May 1997.

6 Cormack RS, Lebane J. Difficult tracheal intubation in obstetrics. Anaesthesia 1984; 39: 1105-11.

7 Murphy P. A fibre-optic endsocope used for nasal intubation. Anaesthesia 1967; 22: 489-90.

8 Vacanti ChA, Roberts JT. Blind oral intubation: the development and efficacy of a new approach. J Clin Anesth 1992; 4: 399-401.

9 Szekely SM, Webb RK, Williamson JA, Russell WJ. Problems related to the endotracheal tube: an analysis of 2000 incident reports. Anaesth Intensive Care 1993; 21: 611-6.

10 McCoy EP, Russell WJ, Webb RK Accidential bronchial intubation. Anaesthesia 1997; 52: 24-31.

11 Sugiyama K, Yokoyama $K$ Displacement of the endotracheal tube caused by change of head position in pediatric anesthesia: evaluation by fiberoptic bronchoscopy. Anesth Analg 1996; 82: 251-3.

12 Weiss $M$, Schwarz U, Gerber AC Difficult airway management: comparison of the Bullard laryngoscope with the video-optical intubation stylet. Can J Anesth 2000; 47: $280-4$.

13 Shorten GD, Roberts JT. Some applications of fiberoptics in anesthesia. Anesth Clin North Am 1991; 9: 187-93. 